Paper 2081

\title{
HUMOROUS ENGINEERING 101
}

\author{
Larry Cartwright Carnegie Mellon University
}

\begin{abstract}
The Senior Design course is taught to Carnegie Mellon students each fall. This capstone course is required for all Civil and Environmental Engineering majors. The course concentrates on teaching the three levels of the design process by using projects that relate to the core areas of the discipline. This paper will provide an overview of the course with emphasis on the final design/build project. This project is humorous in nature and is eagerly anticipated by the students. Five examples of past projects will be presented. The paper will conclude with a discussion on creating these projects and the benefits they provide.

\section{Introduction}

When people think of Civil Engineering design, they usually think first of designing a bridge. The process of design is much more encompassing. The object of the design does not necessarily have to be an artifact or facility; it may also be a process. A civil engineer may design a bridge, or a building, or a highway intersection, or water or wastewater treatment plant or a process for remediating a contaminated landfill. While the products of these designs are dissimilar, the design process used is the same in each. It starts with a conceptual design, proceeds to a preliminary design and culminates with a detailed design. As teams create designs, team building and presentation are essential parts of the process. The course described herein concentrates on teaching the levels of design, team building and presentation.
\end{abstract}

\section{Course Overview}

The Senior Design course is presented as four projects: an introductory project, a conceptual design project, a preliminary design project and a detailed design/build project. Typical subject areas of the projects are structural, environmental and planning/management. Group progress reports and final reports are required for each project. In addition, each group has one poster presentation and each student has one oral presentation during the semester.

The introductory two-week project is meant to show the students how difficult the design process is. Four or five students are chosen at random to form a group. They are 
presented with a small design/build project, such as the creation of a vertical climbing device. They are required to design the structure and submit written specifications. The specifications are given to another group to build. Each group designs their structure and builds another group's design. There is minimal interaction from the instructors. The intent is to allow the students to flounder; to let them gain an appreciation of the pit falls of the design process and the problems that may arise from dysfunctional groups.

The second project lasts four weeks and emphasizes conceptual design. In order to cross a valley, the concept may be to walk down one hill and up the other side, or to hire a helicopter, or to be a human cannon ball and have yourself shot across or to build a bridge. Design decisions are stressed. These include problem statement elaboration, objectives, constraints and the evaluation criteria. Team building and member roles are emphasized. The students are permitted to form their own groups, as long as there is $\mathbf{1 0 0}$ percent satisfaction among them. Creative techniques such as the Method of Controlled Convergence and Morphological Charts are presented, as are several evaluation techniques.

The preliminary design project is the next four-week assignment. The groups are given a conceptual design and allowed to develop it. As in the previous example, the concept chosen to cross a valley was to build a bridge, the preliminary design would determine the type of bridge and roughly size the members. Additional techniques in synthesis and evaluation are taught.

The final four-week project assignment is a total design project including detailed designs. Using the previous example, the detailed design would specify exact member length and every drilled hole and clip angle. The project is the design/build type and is usually humorous in nature.

Five previous final projects are presented. All presentations include descriptions of problem delivery, problem statement, design, construction/testing and a follow-up section.

\section{I. "Mobile Cow Tossing"}

Problem Presentation. A month prior to this assignment, fliers were posted throughout all campus academic buildings. The fliers stated only "MCT is coming". The font of MCT was similar to MTV, with which all of the students are familiar. One of the course's teaching assistants would go out each Sunday at midnight and, being careful not to be seen, post more of the multi-colored signs. The campus population was baffled. No one had an explanation of the signs' meaning.

On the scheduled day, the fourth project was distributed to the students. The first page was a standard course title page. The second page had only the words, "MCT IS HERE!" The third page proclaimed, 'MOBILE COW TOSSING." There were many smiles as the students read the problem statement. 
Problem Statement. The groups were to design and build flotation crafts large enough to accommodate a trebuchet and a 300-pound man. The man had to be able to maneuver on the structure, to arm the trebuchet and launch a twenty-pound concrete cow as far as possible. The trebuchet would have a 250 -pound counterweight. The allowable materials were wood, closed-cell foam and a variety of hardware.

Design. Several lectures were devoted to naval architecture and trebuchet design. Each group was given an amount of foam capable of providing 900 pounds of buoyant force. They were lectured on the stability of structures on water. The mathematical explanation of a trebuchet was presented. A trebuchet is a double pendulum and was used in the $15^{\text {th }}$ century to launch dead cows into fortified castles. The intent was to introduce disease to the inhabitants of the castle. This method was featured in the movie "Monty Python and the Holy Grail", which has a cult following among many college students. The mathematical solution was simplified to three variables. The students were able to create spreadsheets to predict the optimal penduli length. The trebuchet then had to be structurally integrated with a stable floatable platform.

The instructors supplied all of the necessary hardware for the trebuchet arm pivot and also supplied a 2-foot square damper to absorb the impact of the 250-pound counterweight hitting their structure. Their designs had to accommodate both of these. While all of the structures were similar, they varied in several ways. The lengths and structures of the trebuchet arms varied per group. The vertical support pieces ranged from built-up columns to small trussed-structures. The flotation platforms varied in size and structural layout. Some groups chose to place the flotation foam uniformly beneath their structures, while others opted for an asymmetrical layout to accommodate the location of the instructor relative to the counterweight.

Construction and Testing. The construction took place the day before testing. The students, teaching assistants and instructors devoted the day to laying out, cutting and assembling the structures. The construction area was a sheltered outdoor site next to the testing area. Construction continued until the late evening. Pizza and beverages were provided for all.

The test site was an above ground pool, 20 feet wide by 20 feet long by 3 feet deep. It was lined with 2-ply polyethylene and filled with water from a nearby fire hydrant. The pool was designed and constructed by the instructors and teaching assistants.

The morning of testing was a chilly December day. The water temperature was $38^{\circ} \mathrm{F}$. The testing commenced with the arrival of the instructors and teaching assistants suitably regaled in cow costumes. The university had a photographer and film crew to record the event. The first group lifted their structure and launched it into the pool. The 300-pound instructor boarded the craft and checked its stability. The 250-pound counterweight was brought aboard and attached to the short end of the trebuchet arm. Two practice shots were permitted to fine-tune the length of the rope, which served as the second pendulum. Gravel filled gallon jugs served as test projectiles. The instructor would arm the trebuchet by hanging on the end of the longer pendulum arm, thereby, lifting the 250-pound 
counterweight off the raft. The arm was secured in the cocked position by a small rope. The test missile was attached to the second pendulum and positioned per specification. The instructor cut the small rope, and launched the missile. Following the test firings, the final test was conducted using the concrete cow. The cows were nicely made and brightly painted.

Most of the structures performed very well. They were stable on the water and permitted successful launches of the bovine missiles. However, one craft did not fare so well. Due to instability, it capsized during the cocking phase and the instructor fell into the pool. That result alone assured the success of the project. After all the testing was completed, the winning group had recorded a 45-yard toss of the 20 -pound cow.

Follow-Up. Two months prior to this assignment, the instructors had met on a weekend, bought assorted building materials, and experimented with building a trebuchet. They had recorded the entire testing phase on videotape. This tape was shown to the students in the class following their testing. They found it quite humorous.

For years after this project, pictures of it appeared on web sites and in university brochures and catalogs. 


\section{MOBILE COW TOSSING}

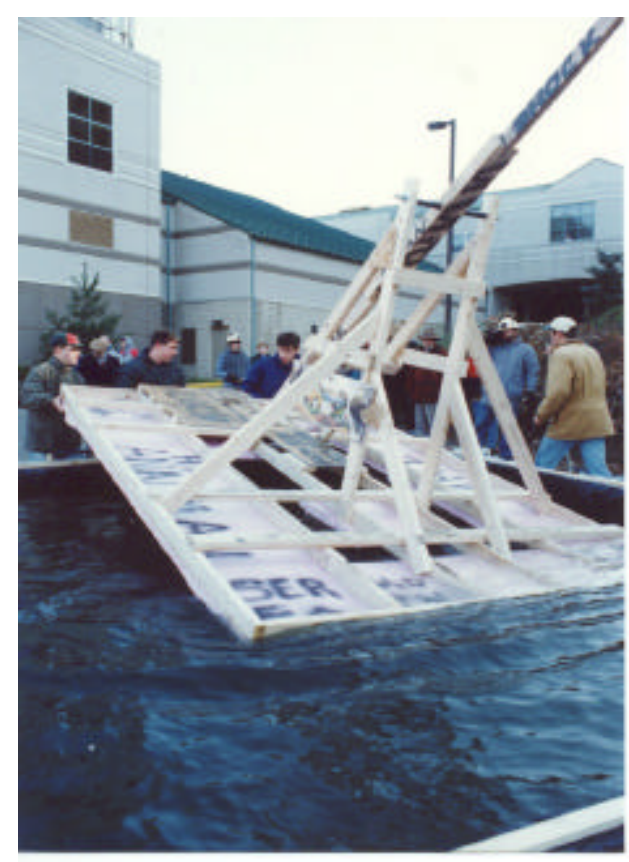

\section{1-Launching the platform}

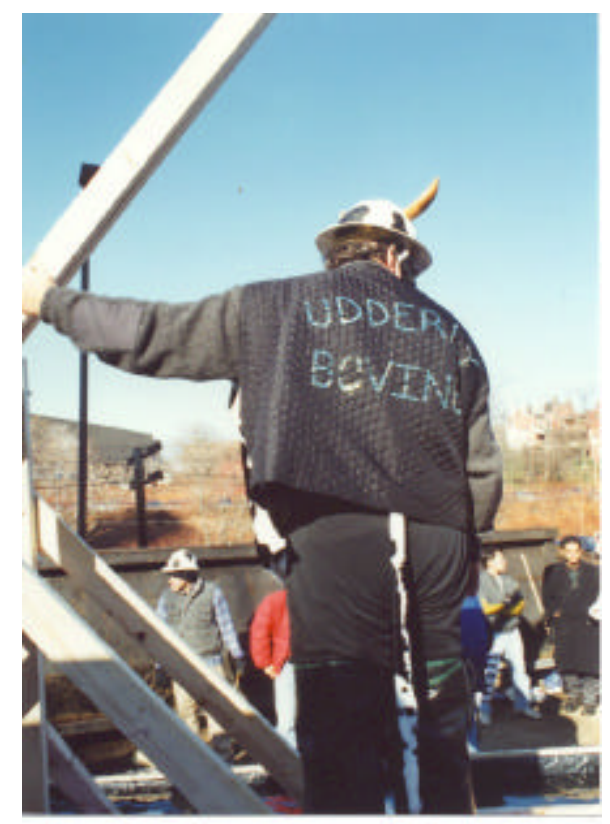

3-Udderly Bovine

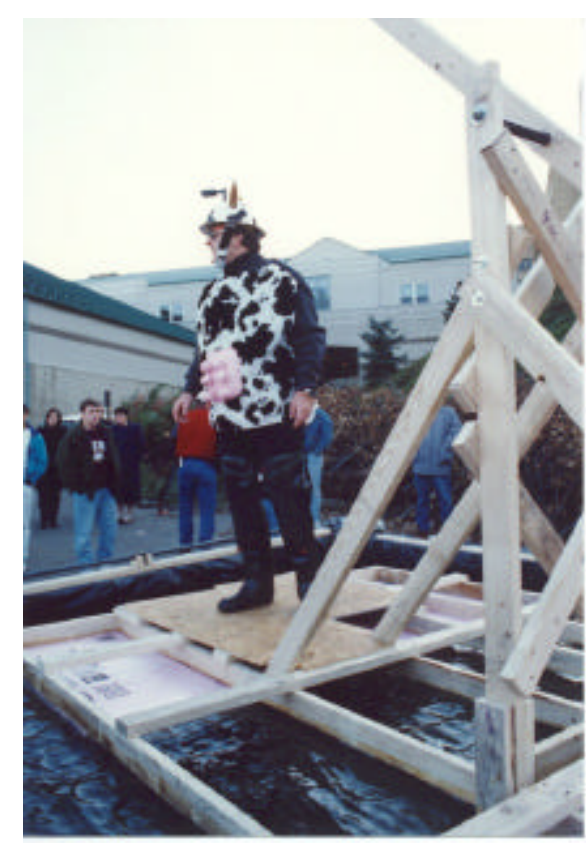

2-Stability testing

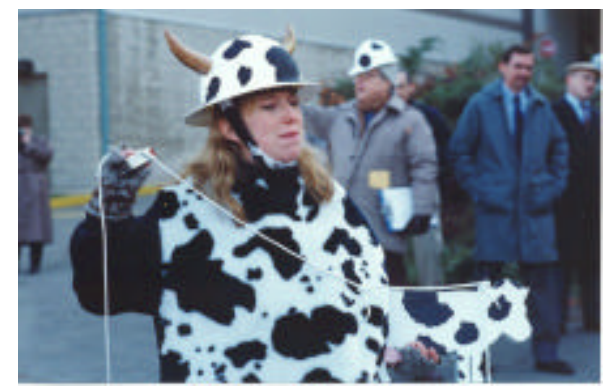

4-Teaching Assistant with cow projectile 


\section{MOBILE COW TOSSING}

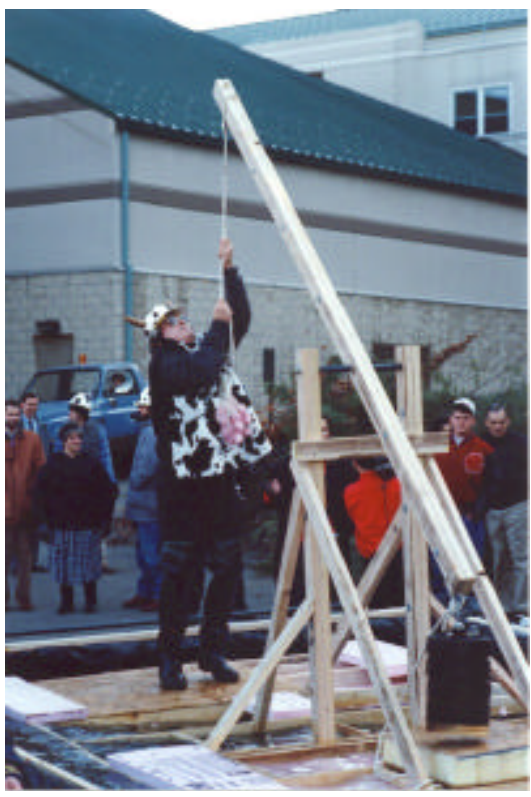

5-Arming the trebuchet

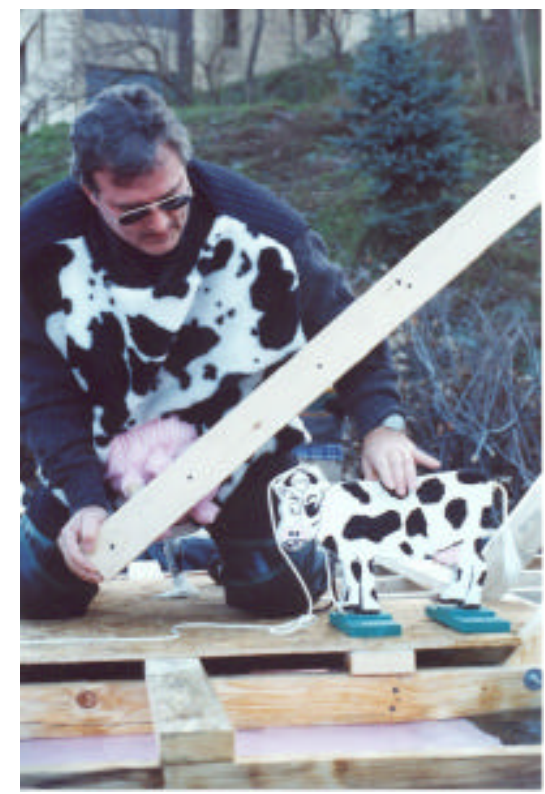

7-Prepare the cow for tossing

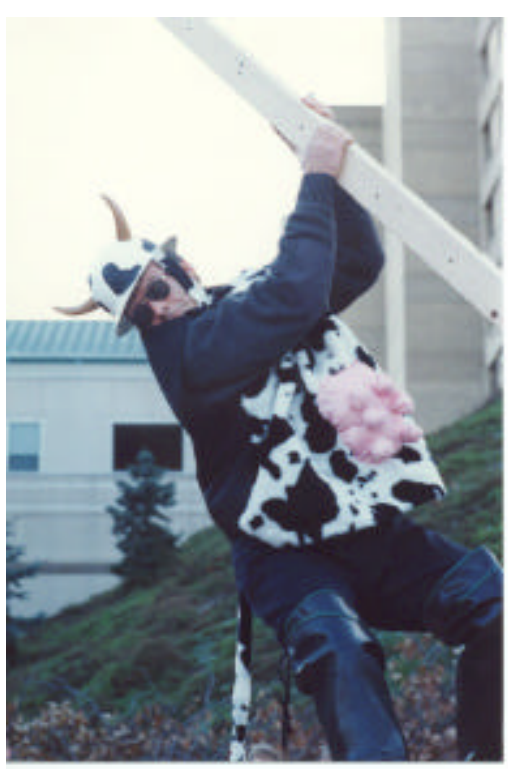

6-Arming the trebuchet

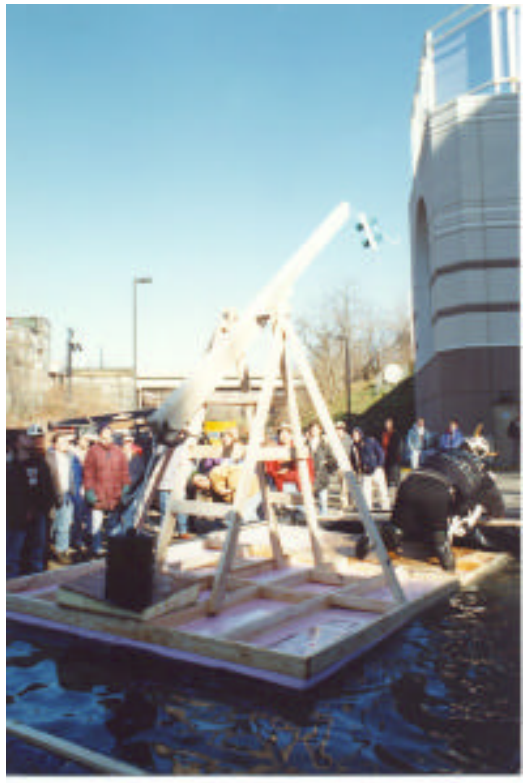

8-Toss in progess 


\section{MOBILE COW TOSSING}

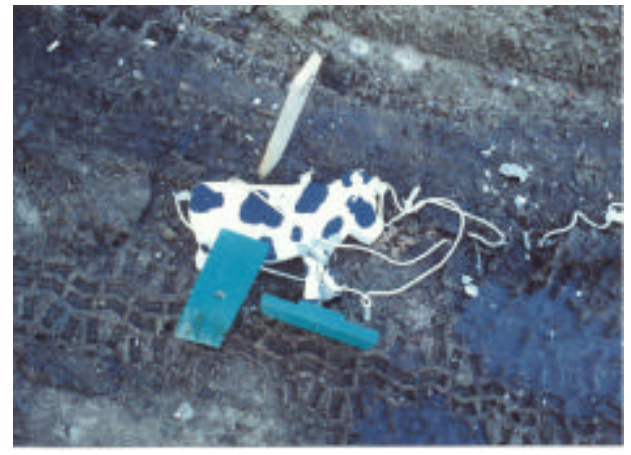

9-The fallen cow

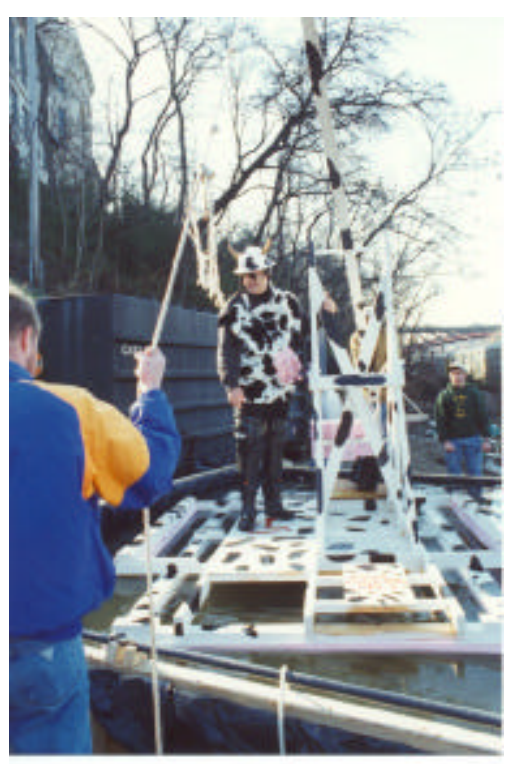

11-Stability testing

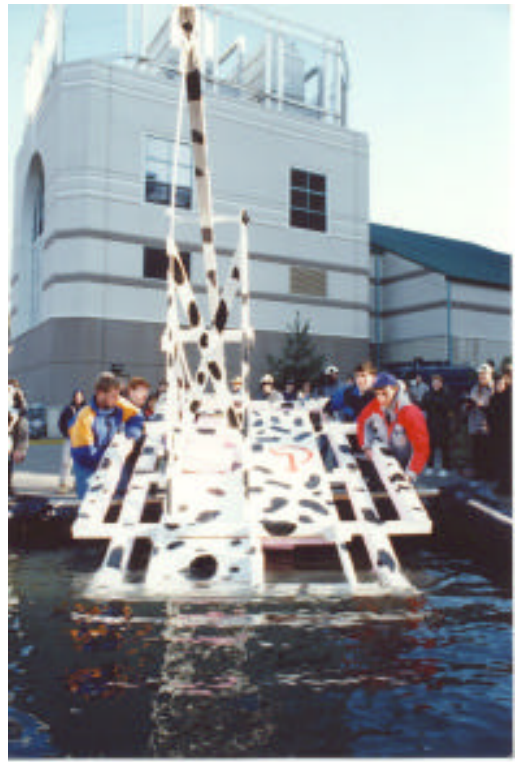

10_Launching "Stealth" craft

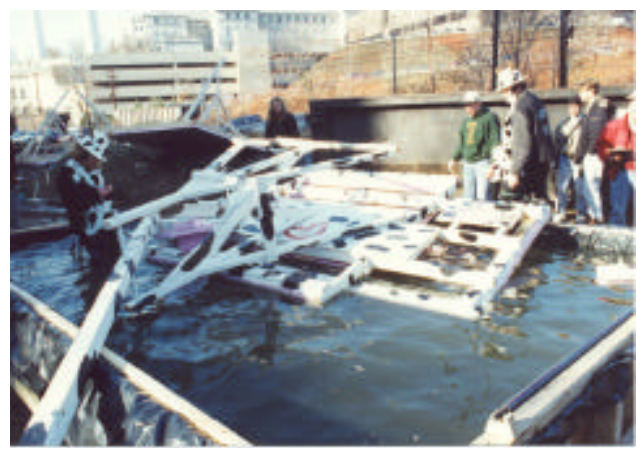

12-Aftermath of Instructor Baptism

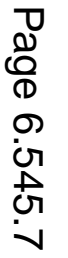




\section{II. "Mission: Preposterous"}

Problem Presentation. This project was a take off on the Tom Cruise movie, "Mission: Impossible" (MI). On the assignment day, the instructor walked into class, gave each group a videotape and left. Each group had to find a way to view the tape. The instructor with the help of a teaching assistant made the tape. The tape mimicked the manner in which the 1960's television show "Mission: Impossible" started. A tape was always given to a Mr. Phelps. He would play it and be informed of a pending mission. After agreeing to the mission and selecting a team, the camera would pan to a fuse being lit and Lalo Schiffrin's theme started to play. Our video started with a hand trying to light a fuse with a match. The fuse did not light. There is a mumbled curse in the background. The hand reappears holding a BIC lighter. The fuse did not light. More background cursing. The hand reappeared bearing a propane torch. Still, the fuse did not ignite. Finally, the hand appeared holding a Beretta pistol. It fired and the fuse lit. The MI theme started on the sound track. (As an anecdote, this part of the video was shot in the university's film studio. The gun belonged to one of our campus police and was loaded with blanks. During filming, the fuses were prevented from igniting by saturating them with water. The muzzle flash of the pistol actually did light a dry fuse.) The video next panned to the rear of a high-back chair situated behind a large desk. A man seated in the chair started to speak. He described the proposed mission, the retrieval of a computer disk from a CIA mole. A picture of the mole with an obviously fake handlebar mustache appeared on screen. (The mole was actually the Civil and Environmental Engineering Department Head.) The voice continued to describe the mission. At the end of his prologue, the chair slowly turned around again. Seated in the chair, was a man dressed in a shirt and tie, wearing a baseball cap with gold letters saying "THE PREZ". This man also had a large handlebar mustache. His somber look slowly changed to a huge smile. He held up both hands giving victory signs. The camera faded to another office. As per the MI formula, Mr. Phelps was viewing $8 \times 10$ pictures of potential team members. Each person, whether male or female, had on the same fake black handlebar mustache. (All of the people were campus notables.) Mr. Phelps made his selection. The video faded and the film credits appeared. (As an anecdote, the man in the seat was our then President, Robert Mehrabian. The video was shot in his office 3 months prior to the assignment being given. He did have a large handlebar mustache and was very gracious in allowing us to mimic him.)

Problem Statement. The problem statement was given to the students in form of a blueprint and multiple communiqués. (The blueprint was actually the first floor of the Civil and Environmental Engineering Laboratories that had been relabeled to represent a floor of CIA Headquarters in Langley, Virginia.) The communiqués were a series of letters between the Preposterous Mission Force (PMF) and Ethan Hunter, the man selected by Mr. Phelps. (A 300-pound instructor portrayed Ethan Hunter.) All of the pertinent information concerning the mission was in the text of the letters. The letters were liberally stamped with "TOP SECRET'.

The mission was to retrieve the computer disk. As per the movie, the computer facility would be accessed through an overhead air duct. (Tom Cruise lowered himself through an 
opening in the duct.) In our project, the groups had to design small portable bridges, that would breakdown and fit into a First-Aid kit. The kit would be taken into the facility, the parts would be assembled into the bridge and Ethan Hunter would carry it through the ductwork. He would use it to span a six-foot opening, crawl across it, retrieve a computer disk and return to the duct entrance. The entire mission was timed. The available materials were 1 1/ 1 1/inch lightweight perforated steel angle, $1 \times 3$ inch pine, 1/8 inch steel cable and assorted hardware. Each group was provided with an empty $2 \times 2$ foot $x$ 9inch First-Aid kit, painted white with a large red cross on the outside.

Design. The students had to design their bridges such that all of the components and assembly tools fit into their First-Aid kit. Only hand tools were permitted. As the mission was timed, designs with multiple members required longer assembly times. The designs included steel trusses, steel and cable suspension bridges, built-up beams and pre-stressed cable and steel structures.

Testing. The testing site was a 3,000 square foot lab that was altered to match the false blue print. A fifty-foot length of ductwork was constructed on the floor of the room. It had a $4 \times 4$ foot cross-section and included both a right-hand and left-hand turn. (These posed constraints for the designers as their structures would have to be maneuvered around the corners.) Near the end of the fifty-foot length, the duct passed over an existing six-foot hatchway in the floor. Below the opening was a fifteen-foot drop to the floor below.

Video cameras were mounted in openings at each corner and at the end of the duct. The cameras fed video monitors located around the room. This allowed viewers to monitor the actor's progress through the ductwork, as per the movie.

One by one, the groups assembled their bridges and the instructor completed his roundtrip mission through the ductwork. The prestressed cable bridge was assembled in less than 30 seconds, while the assembly time for a truss was 8 minutes. An audience of about one hundred people watched the event via the monitors. The designs were varied and only one failed. To the audience, it was amusing. The camera at the end of the duct showed the instructor maneuvering the bridge around the last corner, approaching the floor opening, spanning the bridge across the opening, and cautiously starting to crawl across. The structure failed catastrophically and the instructor fell through the opening. He just instantly disappeared from camera view. Fortunately, he was wearing a safety harness roped to an anchorage. He only fell several feet before stopping. The video was very dramatic.

Follow up. A local reporter and cameraman recorded the entire event. The next day, there was an article and picture of the test on the front page of the Pittsburgh Post-Gazette. It was a slow news day. 


\section{MISSION: PREPOSTEROUS}

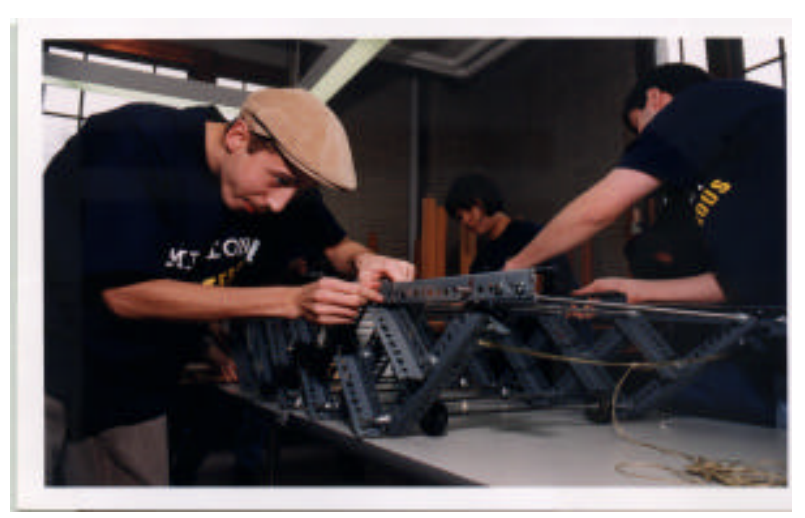

1-Assembling a bridge

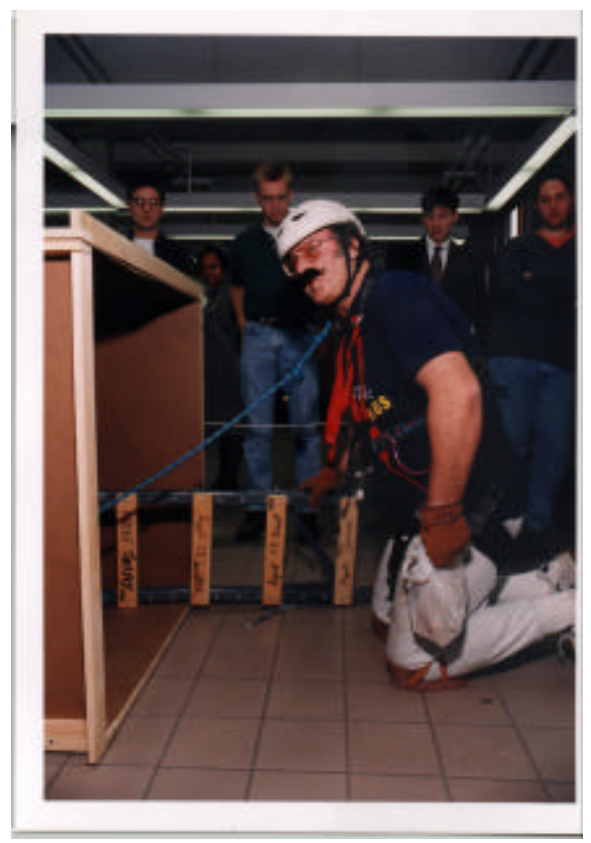

2-Mustached Instructor enters ductwork

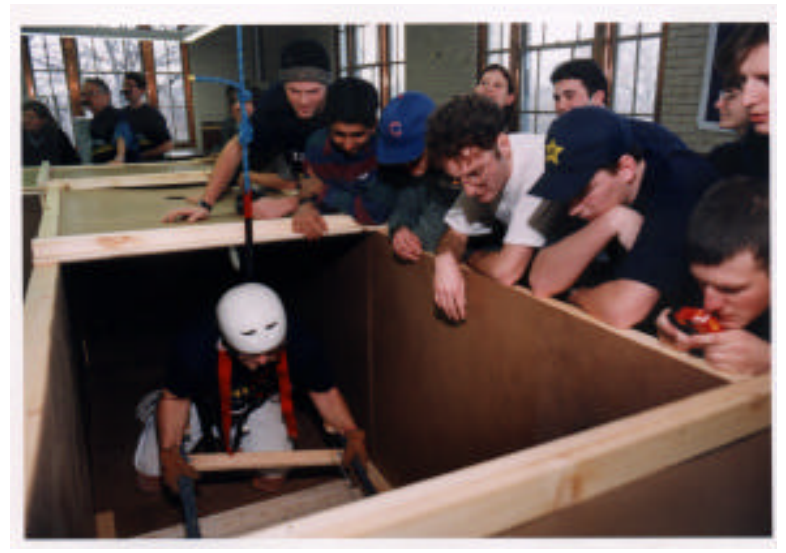

3-Instructor positions bridge over opening

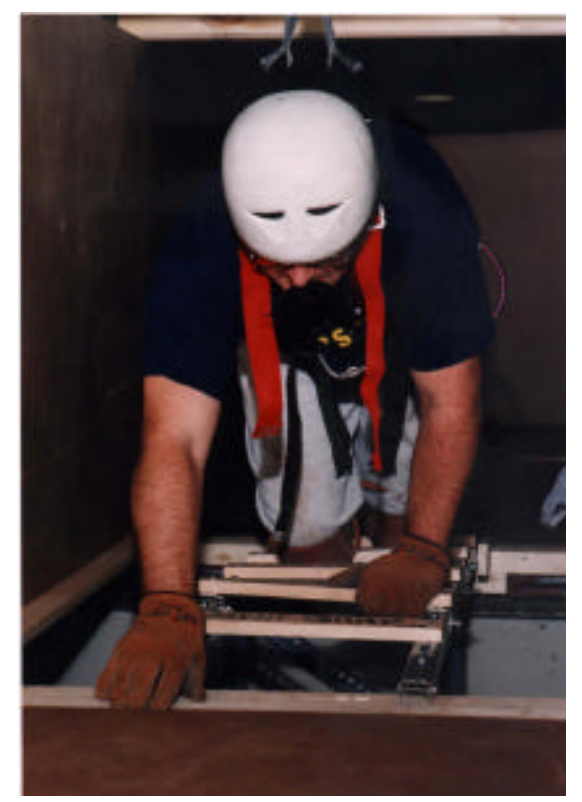

4-Instructor crosses bridge

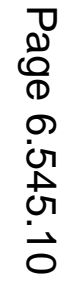




\section{III. "Rube Iceberg P.D.S."}

Problem Presentation. The instructor walked into the classroom on the day of the assignment. He was pushing a four-wheel dolly loaded with large pails. There was a pail for each group. Each pail was filled with a 60-pound block of ice. Visible in the ice was a small plastic tube. The instructor left the room. The students had to extricate the plastic tubes. They contained the problem statements.

Problem Statement. The problem statement started with a one-page biography of Rube Goldberg. He was a Berkeley-trained mining engineer who gained fame as a cartoonist. His cartoons portrayed a series of individual devices/mechanisms when initiated would perform a mundane task. The initials P.D.S. remained unexplained.

The problem was to design and build a reinforced ice bridge. The bridge had to span a distance of 6 feet, stand 2 feet high and 4 inches wide. It had to bear a moving 16-pound load on its top surface. As it had to be lifted by the group into the testing rig, casting a solid block would result in a structure weighing 200 pounds. They had to design a structure light enough to be handled by 2 persons. They were given the material specifications of ice and stainless steel rod. The steel provided tensile reinforcement and was 0.06 inches in diameter. The groups had to design the bridge plus the formwork necessary to cast it.

Design. Each group was provided a set of lined rigid forms with interior dimensions of 6 feet long, 2 feet wide and 4 inches deep. They had to design an ice structure that would be cast within the forms. The shape of their structure was defined by 4 inch thick foam inserts which were glued to the bottom of the formwork. The bridges were cast flat and erected vertically for testing. The solutions were arched bridges, trussed bridges, and simple frames with exposed steel tension reinforcing. Not all of the groups chose to use the available reinforcing.

Construction and Testing. The completed forms and all of the students were bused to a frozen food locker several miles from campus. Arrangements had been made with the owner of the facility several months in advance. The food locker was $100 \times 200$ foot with a 30-foot ceiling. The interior temperature was $10^{\circ} \mathrm{F}$. All of the forms were carefully leveled and slowly filled with water. They were allowed to freeze for 48 hours.

The class was bused again to the food locker to test their structures. Their bridges were carefully removed from the forms and the foam inserts were removed. They were moved to an outer room where the testing took place. The testing fixture was a "Rube Goldberg" system designed and constructed by the instructor. It measured 25 feet long and consisted of 12 stages. The ice bridges formed the middle stage of the fixture. The stages were as follows: 
1) Student throws a tennis ball striking a target;

2) the target support pivoted and released a wheeled Baby Goofy dog;

3) the Baby Goofy dog ran along a track and bumped a weighted bottle;

4) the bottle fell from a ledge and an attached string pulled a detonating lever;

5) the detonator released a 16 pound bowling ball;

6) the bowling ball rolled down a ramp and across their ice bridge striking a pad;

7) the pad pushed a boxing glove;

8) the boxing glove hit an igniter on a propane torch;

9) the propane torch lit and burned a string;

10) the burnt string released a weight;

11) the falling weight activated a catapult;

12) the catapult launched a banana cream pie into the instructor's face.

Hence, the "Rube Iceberg P.D.S." stood for "Rube Iceberg Pie Delivery System".

Follow-up. The instructors sampled many pies that day. 


\section{RUBE ICEBERG P.D.S.}

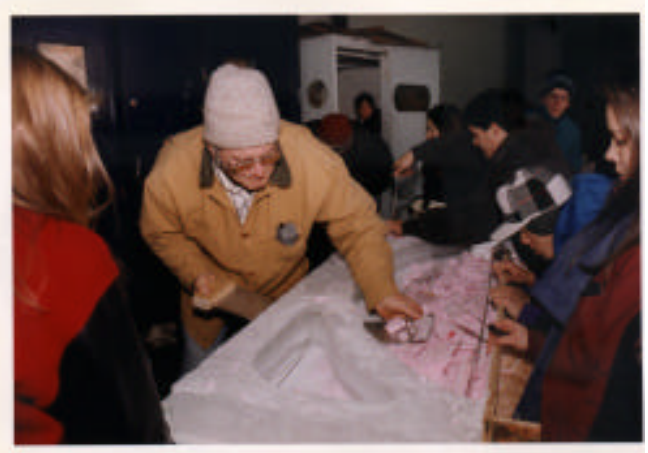

1—Removing ice bridge from forms

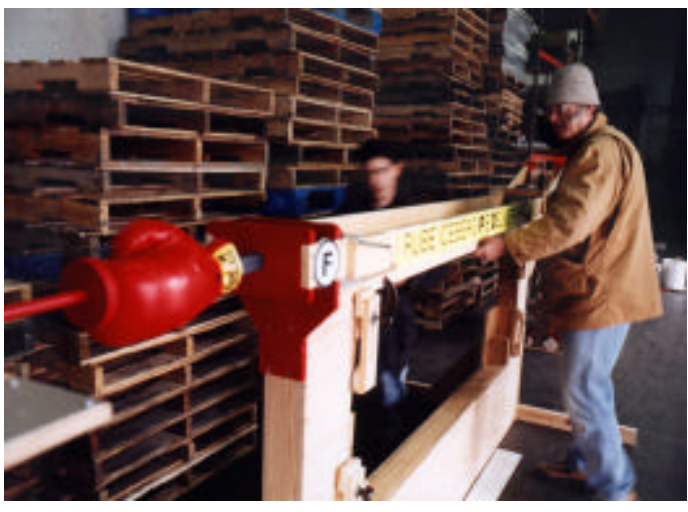

3-“Rube Goldberg" test setup

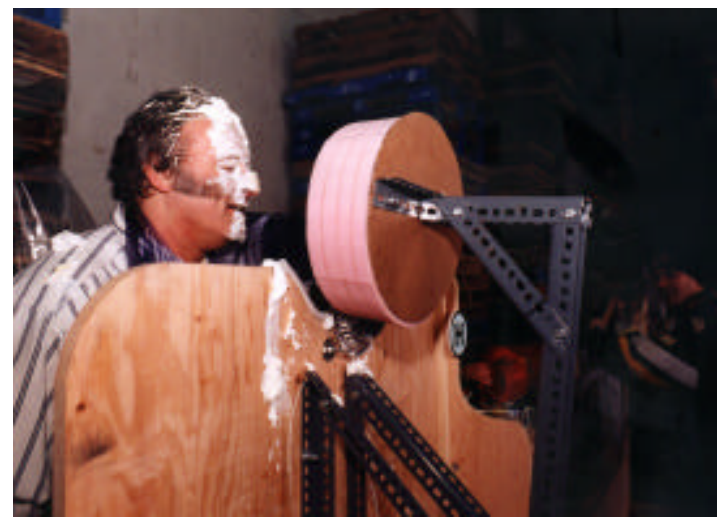

5-A successful pie launch

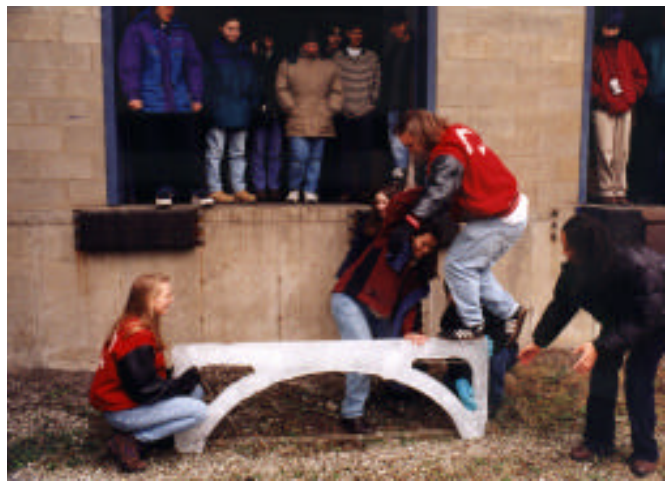

2_-Informal testing

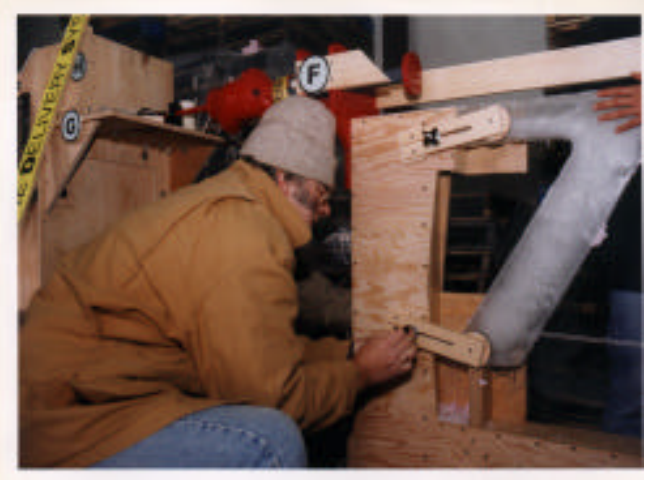

4-Mounting ice bridge for testing

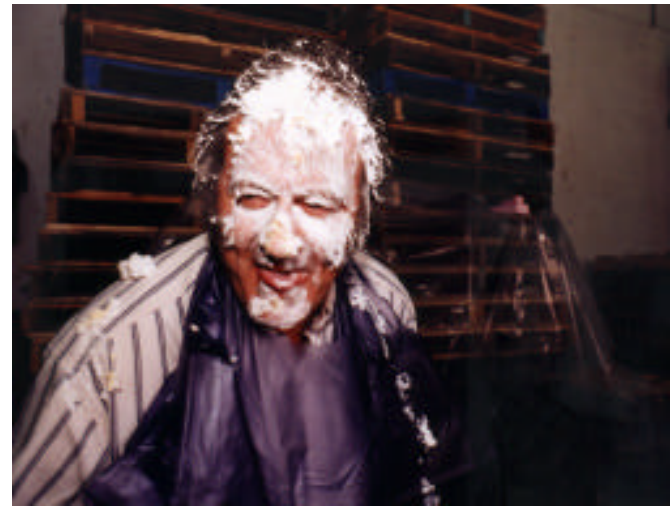

6-Banana Cream Pie Facial 
Problem Presentation. The instructor walked into class and wrote two numbers on the blackboard. They were a longitude and latitude. He laid a portable Global Position Satellite (GPS) receiver on the front table and left the room.

The class took the receiver outside and figured out how to use it. As they walked around campus, the subtle changes noted on the receiver indicated that the specified destination was distant from their location. Almost the entire class piled into 6 cars, formed a caravan and started tracking the final destination. They drove around Pittsburgh and slowly zeroed in on the target. The location was the Highland Park Lock and Dam on the Allegheny River. The problem statements were in a waterproof package attached to a chain-link fence by the dam. The package was placed there with the permission of the U.S. Corps of Engineers, who operated the lock. (The students' hour-long caravan experience really helped bond the members into cohesive groups.)

Problem Statement. The groups were to design and construct cofferdams. The enclosed area was specified as 35 square feet. Each group would install their structure in a pond, have the interior water pumped out and have the structure stand freely for one minute. They were given a budget of $\$ 150$ and no constraints as per material selection. They were given the permeability of the sand at the bottom of the pond.

Design. The students had to design a structure that withstood the hydrostatic pressure of a two-foot depth of water. In addition, they had to prepare a flownet using the hydraulic conductivity of the soil. They had to predict the inflow of water from the porous bottom in the cofferdam as the pumps were de-watering it. Several groups designed wooden structures. As these were buoyant, they had to purchase sand bags from the instructors to weigh the structures down. In some cases, the structures required hundreds of pounds of sand bags. It was a losing battle; the more wood they used, the stiffer the structure, the more buoyancy they created, the more sand-bags they needed, and the more loading and unloading of bags. One structure was designed using PVC pipe and fittings. The frame was octagonal with holes drilled in the upper and lower support members. This allowed the structure to flood and sink in the water, thereby, minimizing additional counterweight. The "membrane" they chose to encompass their frame was duct tape, (16 rolls in fact). Another group fabricated their circular cofferdam from PVC sheet that was curved to form a six-foot diameter cylinder. The ends were overlapped and glued together with PVC cement. It was intended to install the cylinder in the pond then fix the shape by driving stakes along the inner perimeter into the pond bottom. It would then be dewatered.

Testing. The test site was a one-acre pond in a nearby city park. Three months prior to the assignment, the instructors had received permission to modify the inlet of the pond. The university's backhoe operator created a separate small pond at the inlet. It was about forty feet in diameter and two feet deep. 
The testing took place on a brisk December day, over a six-hour period. Each group had 30 minutes to install their structure, have it de-watered, tested and removed. The group members were provided with hip boots. Entry into the chilled waters was necessary. The structure was positioned and anchored (most chose sand bags). The intake pipes from two 100-gpm pumps were placed inside and the structure was dewatered.

Once the structure was empty, i.e., the seepage in equaled the discharge out of the pumps, the structure was tested. A lightweight pallet was placed in the cofferdam on the base of the pond. A 300-pound instructor, clad in a dry suit, stepped into the structure and lay down on the pallet. He remained there for one minute below the water level. If the structure remained intact and he stayed dry, then the test was successful. If the structure could not be pumped out or if it collapsed, then the test was a failure. Three of the structures failed. The PVC frame and duct tape cofferdam could never be dewatered. There were too many tiny voids in the duct tape membrane. The PVC sheet structure marginally passed. As it was being dewatered, its shape slowly changed from circular to an amoebic shape. The interior stakes were incapable of maintaining the round shape. The instructor did, however, manage to lie on the bottom for one minute.

Follow-up. Dry suits really work and hot chocolate is a wonderful thing in December. One group's design was shaped as a coffin and was aptly dubbed the "coffin dam". A picture of the instructor, lying in the bottom of the "coffin dam", with his arms crossed over his chest appeared in the local newspaper. 
JUST DAM IT!

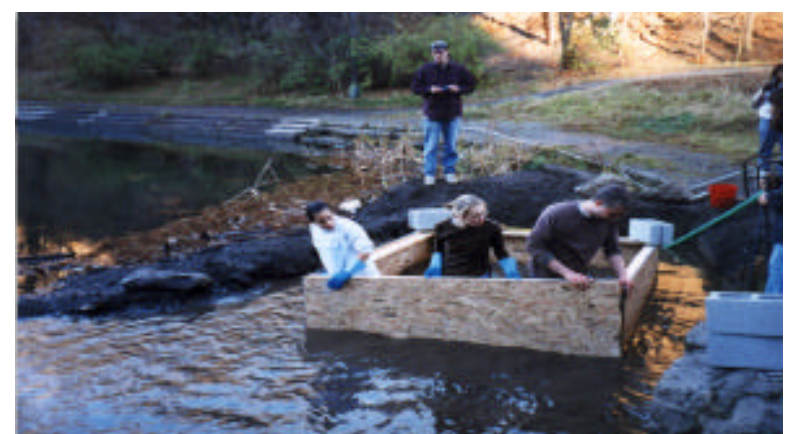

1-Installing a coffer dam

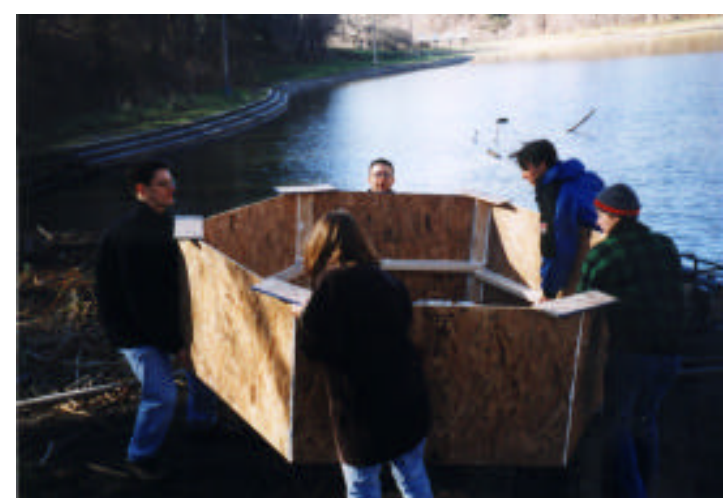

3-Installing a hexagonal coffer dam

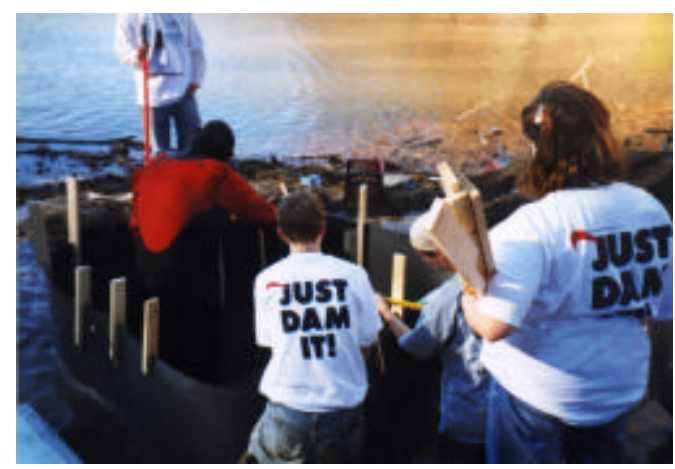

5-Circular PVC coffer dam changes shape

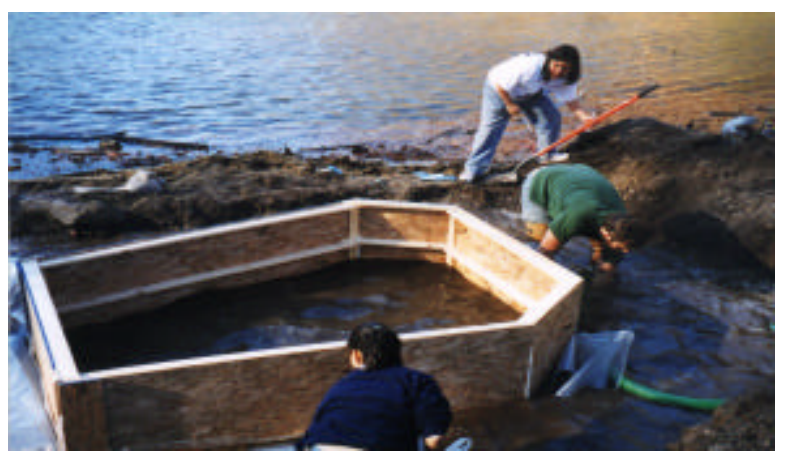

2-Installing the "Coffin Dam"

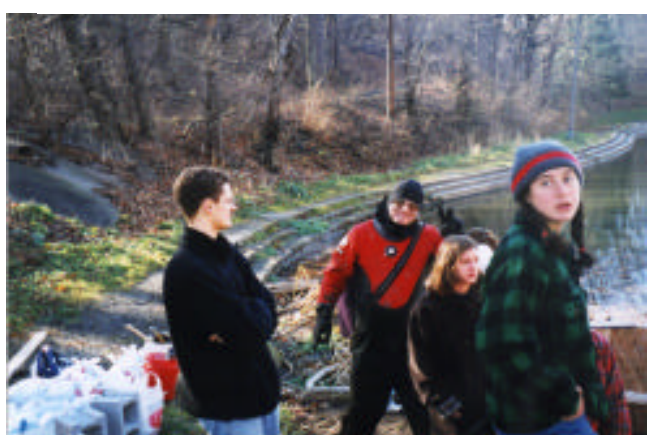

4-Instructor, dry suit awaiting wet suit

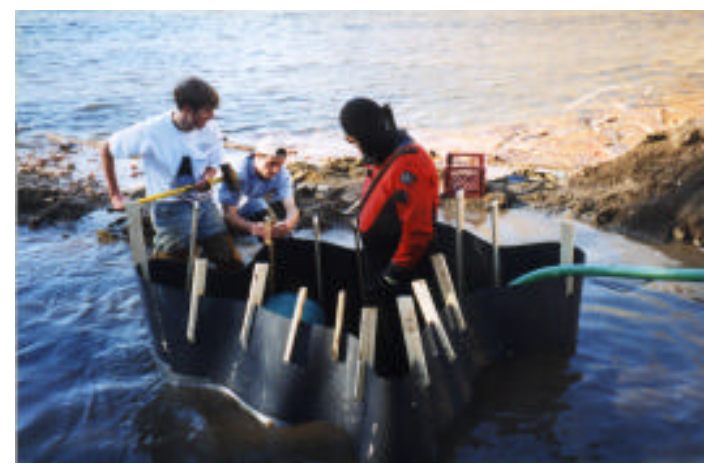

6-PVC "amoeba" is dewatered

7-Score:

Student "1"

Instructor “0”"

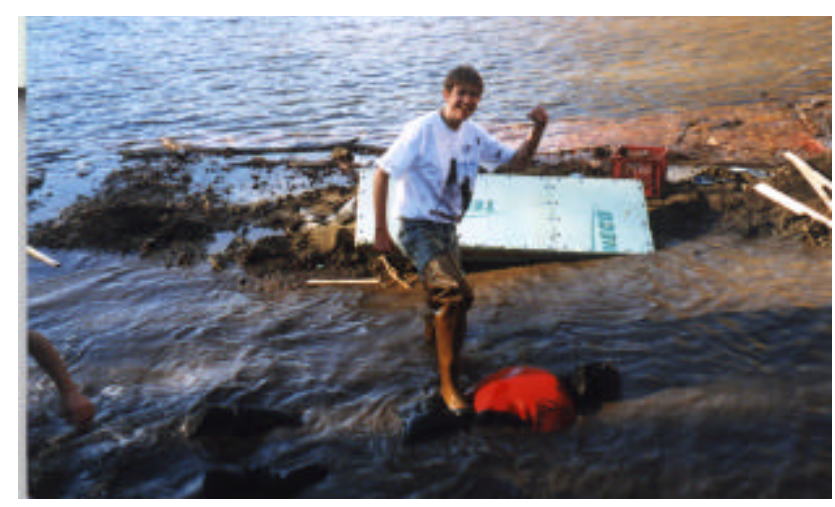

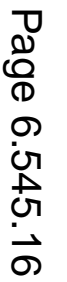


V. "Woolly Bully"

Problem Presentation. On the day the assignment was to be presented, the instructor devoted the first ten minutes of class talking about the random problems of the previous project. He was stalling. The students grew relentless. The door opened and a uniformed man rushed into the room shouting "Speedy Delivery! Speedy Delivery!" The students were startled. The man was Mr. McFeeley from Mister Rogers' Neighborhood. He was clad in his postal outfit and from his leather pouch; he took a sealed envelope for each group. He stayed there for almost an hour talking to the students, having his photograph taken numerous times, and generally, being charming. (As an anecdote, it had taken the instructors four months to arrange this appearance. WQED, the PBS station where Mister Rogers' Neighborhood is filmed, is adjacent to the Carnegie Mellon campus. The instructors had been trying to arrange for Mister Rogers to deliver the assignment. Months of arranging with his publicist, David Newell, fell through two weeks before the assignment. Mister Rogers would be filming in Seattle when we needed him. Sensing the disappointment, Mr. Newell asked if Mr. McFeeley would be a suitable substitute. We said it would be wonderful. He then informed us that he was Mr. McFeeley. We had been talking to him for months and never knew.)

Mr. McFeeley did not deliver the problem statements. He delivered the clues. The envelopes contained a crossword puzzle for each group. The puzzles were created by the instructors and had over 120 words. These were numerous clues about Carnegie Mellon, and also an individual clue for each of the 35 students in the class. Thirteen blocks on the puzzle were highlighted. With the correct puzzle solution, these thirteen letters were known. They formed an anagram, which when rearranged, spelled CIVIL ENGINEER. These words were inserted into a web site address to find the problem statement. The problem title was "WOOLLY BULLY".

Problem Statement. Each group had to design and build a vertical structure to tether a 300-pound bull. The structure could not be anchored to the ground and should be as light as possible. Extra credit was given for the least expensive structure, the lightest structure, and the structure with the smallest footprint. There were no material constraints, a height requirement and a $\$ 100$ maximum budget.

Design. The students had to make an initial decision. To design a structure with a minimal footprint, it would be very heavy. To design a lightweight structure, would require a large footprint to resist tipping. The options were mutually exclusive - well, almost. While there were several structures that had cast concrete centers for mass and several lighter structures each with a large footprint, one group designed a structure that was both lightweight and had a small footprint. Their structure had a pivoting arm that articulated outward when tensioned by the bull. At full extension, the arm end dug into the ground and prevented tipping. As the tension diminished, a spring would retract the extended arm. The center pivot was a truck wheel and bearing assembly retrieved from a junkyard for several dollars. One of the most creative (and least expensive) structures was made of used truck tires. Several tires were purchased and tests were conducted to determine the frictional component of a tire sliding on its side. The entire structure (shaped like an 
Absolut vodka bottle and appropriately named) was lashed together with nylon strapping. Tension tests were conducted on prototypes to determine the shear resistance of a strapping/tire assembly. The entire structure weighed about 1300 pounds and cost $\$ 37$.

Testing. The test site was a quadrangle on campus. The structures were lined up waiting the test phase. The instructors and teaching assistants made a grand entrance dressed as a bull, a cow and two matadors. Each structure was tested statically and dynamically. A ten-meter bungee cord was attached to the structure and to a harness on the bull. The bull walked away from the structure until the cord was taut. He then leaned forward. If the structure did not tip over, then the dynamic test was attempted. The dynamic test consisted of the bull starting out by the structure, still tethered by the bungee cord and running away as fast as possible. He stretched the bungee cord as much as he could. While he lifted several of the structures off of the ground, the bull was incapable of tipping any of the structures over.

Follow-up. As an anecdote, the 300-pound bull was a reasonably strong beast. However, it was discovered that strong beasts have little strength when being pulled backwards. As the bull stretched the bungee cord to the limit, he could not sustain the force. The cord would spring back and drag the bull backwards over the ground. After numerous draggings, a trip to the chiropractor was scheduled for the bull. 


\section{WOOLLY BULLY}
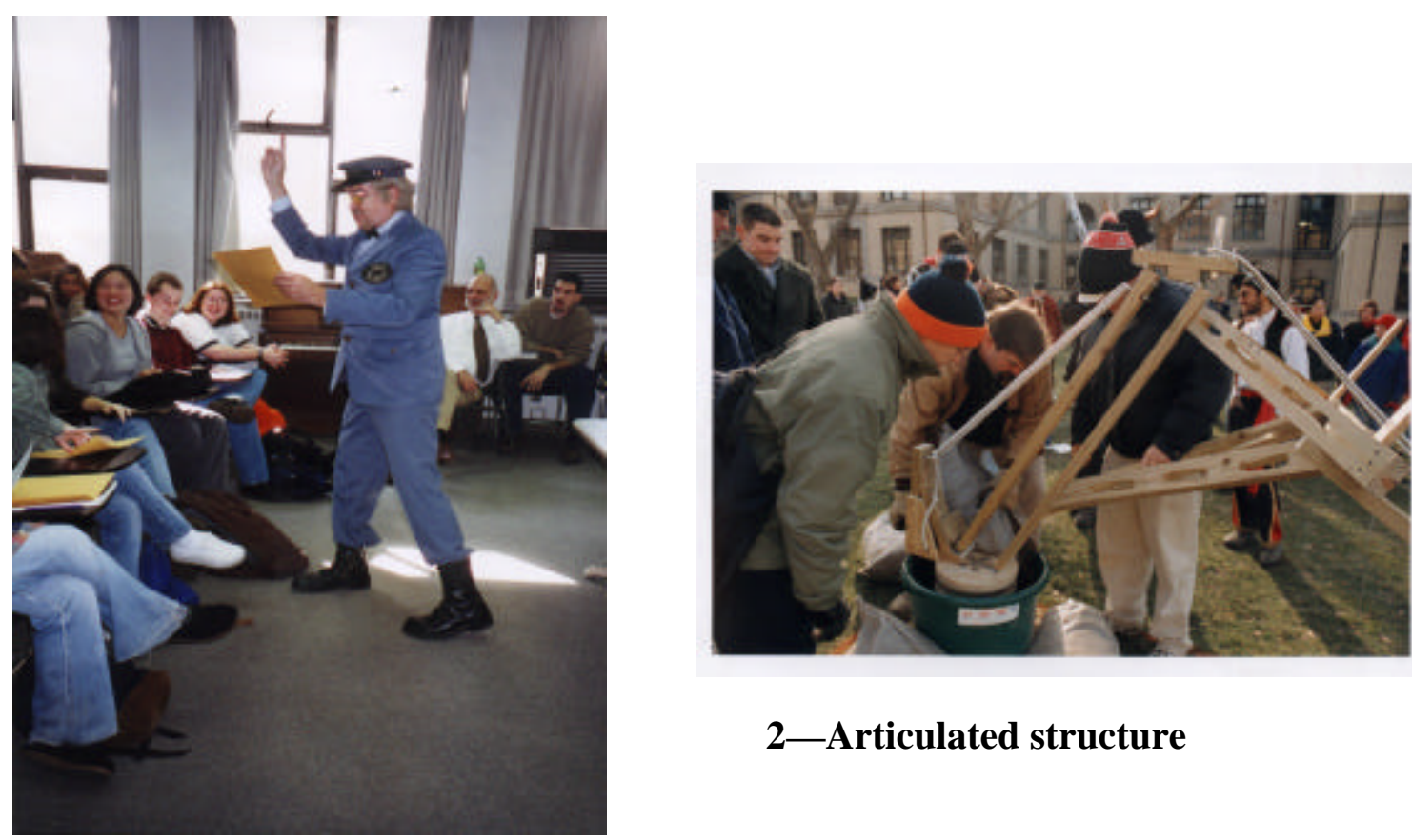

2-Articulated structure

1-Mr. McFeeley delivers the clues
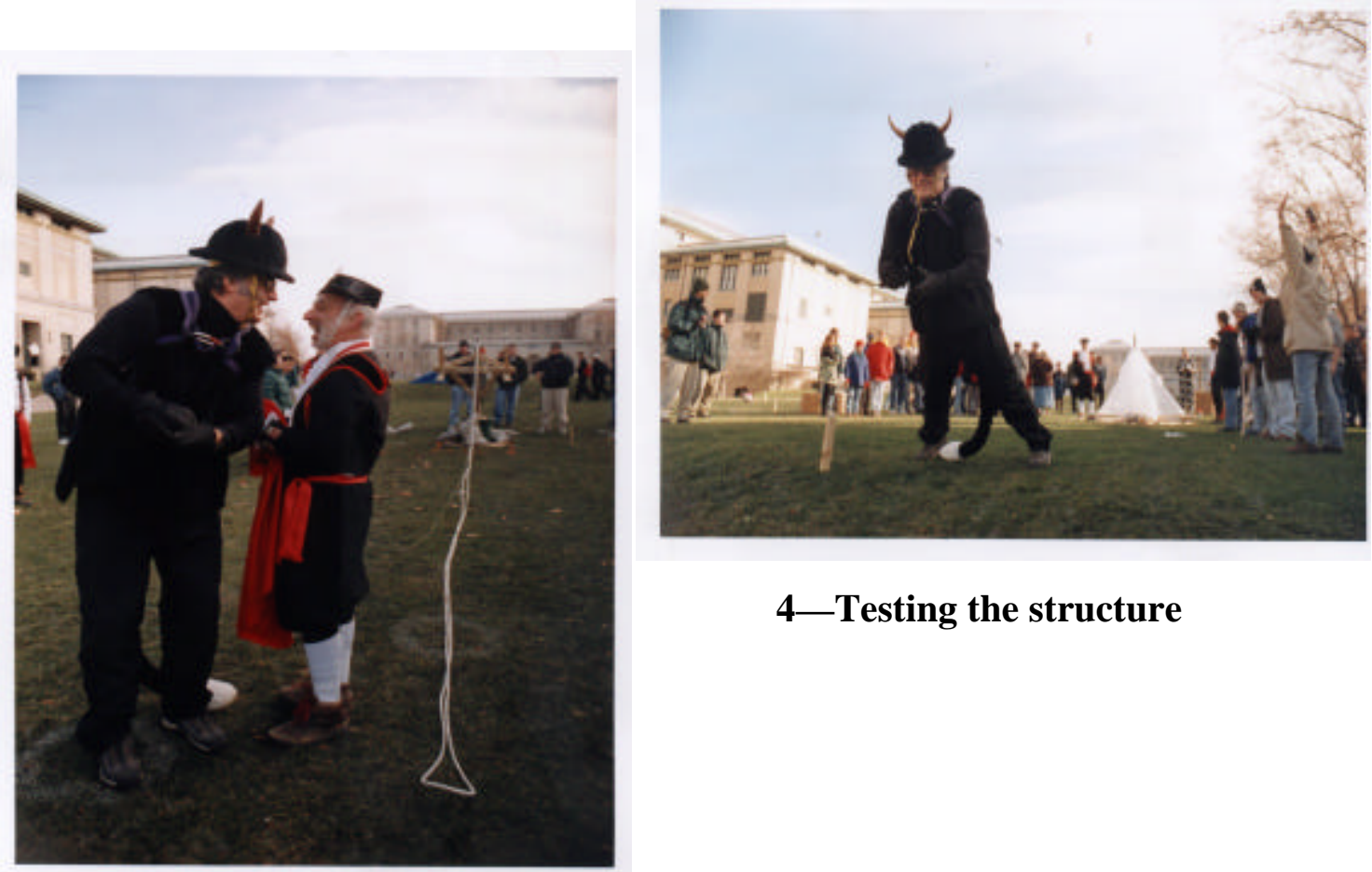

4-Testing the structure

3-Instructors prepare for static test

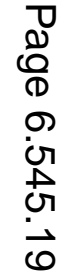




\title{
WOOLLY BULLY
}

\author{
12-401 PROJECT 4
}

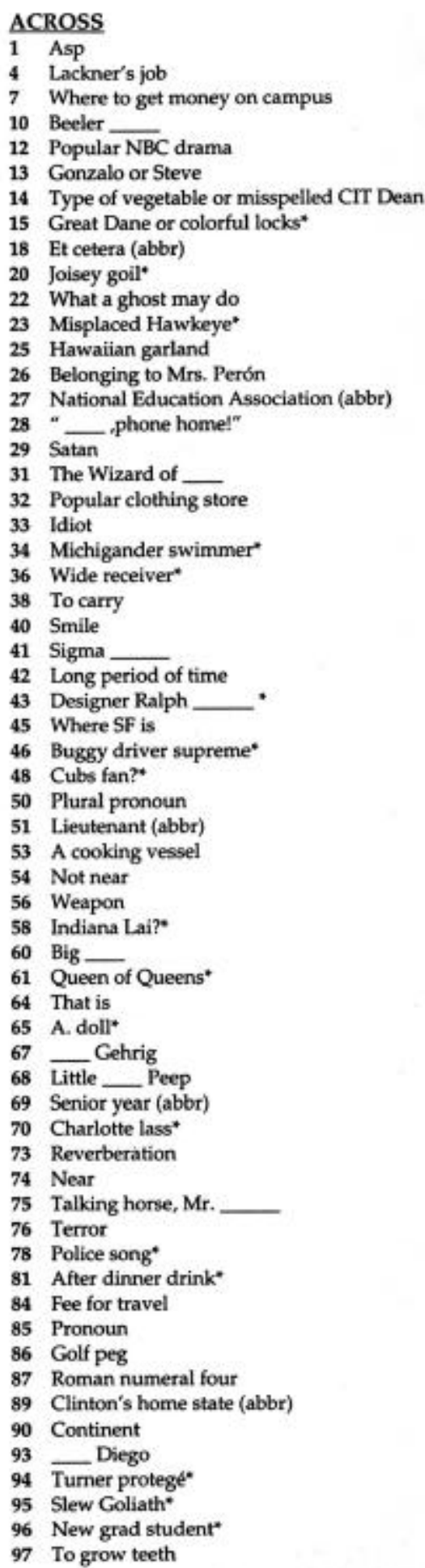

\begin{tabular}{ll}
\multicolumn{2}{l}{ DOWN } \\
\hline 1 & "A Streetcar Named Desire" role \\
2 & Kneeds to be an attorney* \\
3 & Knock out (abbr) \\
4 & Erie \\
5 & 1901 car creator \\
6 & Prefix relating to air \\
7 & Exclamation \\
8 & Texan* \\
9 & Minute (abbr) \\
10 & Saint (abbr) \\
11 & Joined Project 3* \\
12 & Cartoon scream \\
14 & Center of Beta** \\
15 & Can really Thai one on!* \\
16 & HateS pine?* \\
17 & Future architect* \\
19 & Fall apple drink \\
20 & Kisses the Blarney Stone* \\
21 & California babe* \\
24 & Snakelike fishes \\
30 & Georgia peach* \\
33 & Hairy coat of a mammal \\
35 & Enjoyment \\
37 & -Yo Ma \\
39 & PH107E namesake \\
40 & Festivity \\
41 & Treaty organization \\
43 & Not a RH pitcher \\
44 & Woman in a religious order \\
46 & Terrapin* \\
&
\end{tabular}

47 Negative

48 Long Islander

49 Conjunction

52 Soils shear strength test (abbr)

53 Circumference / Diameter

54 Emancipated swimmer"

55 Note of the scale

56 Phonetically Jef*

57 The Cola

58 Not a Mini-an*

59 Note of the scale

61 Belonging to Donald Duck's nephew

62 Unit of force (abbr)

63 Neerly a graduate *

65 Sigh

66 Disorderly crowd

69 Volley girl ${ }^{*}$

71 Very small quantity

72 Compass direction

73 Electrical engineer (abbr)

74 Tree covering

77 Opposite of west

79 Consumed food

80 Male name

82 Resident assistant (abbr)

83 Barrier to stop the flow of water

87 Intravenous (abbr)

88 Roman numeral six

91 "Just do _ I"

92 Architectural Engineering (abbr)

*12-401

http://www.ce.cmu.edu/CNILENGINEER 
WOOLLY BULLY
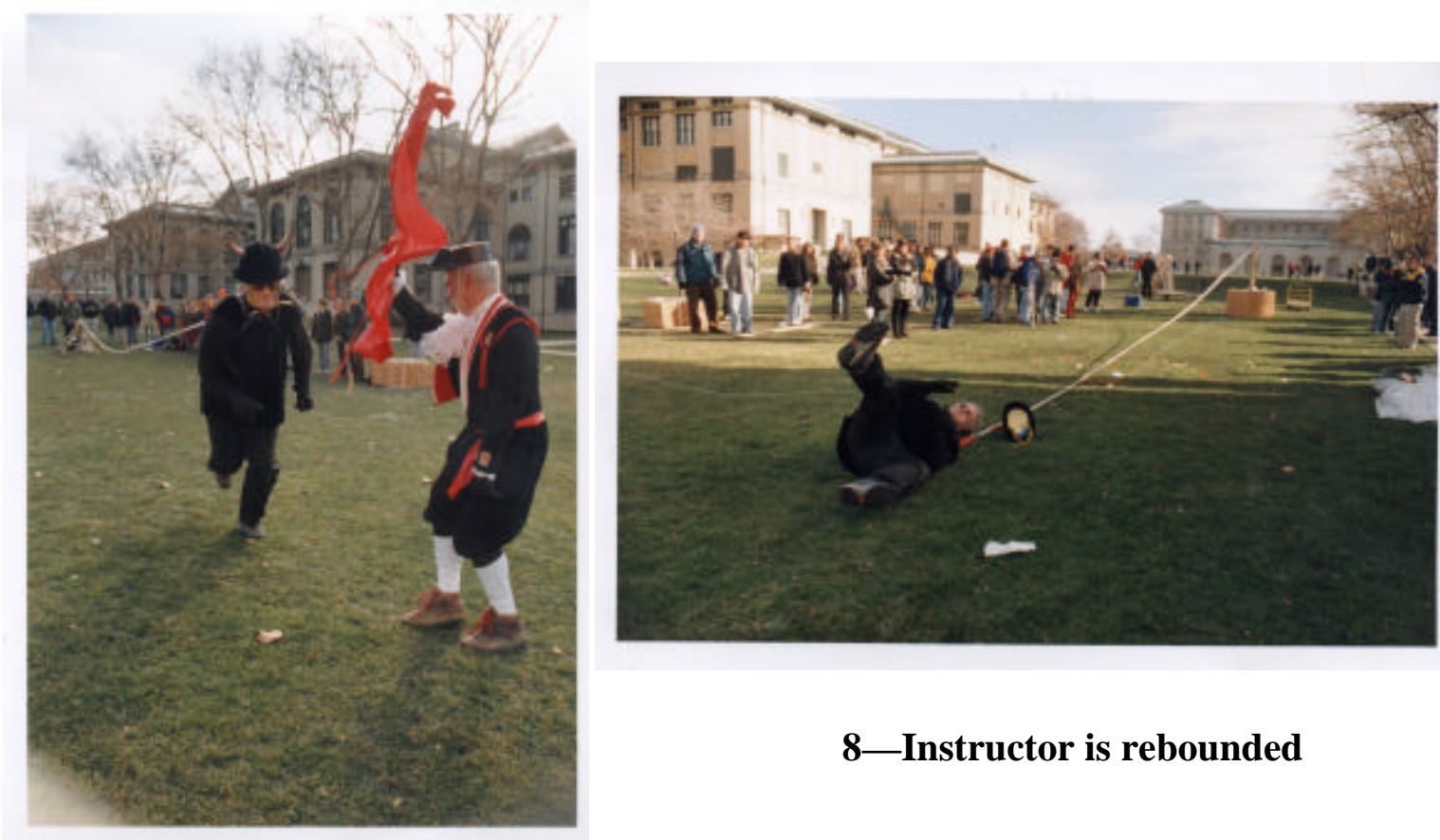

8-Instructor is rebounded

7-Dynamic testing

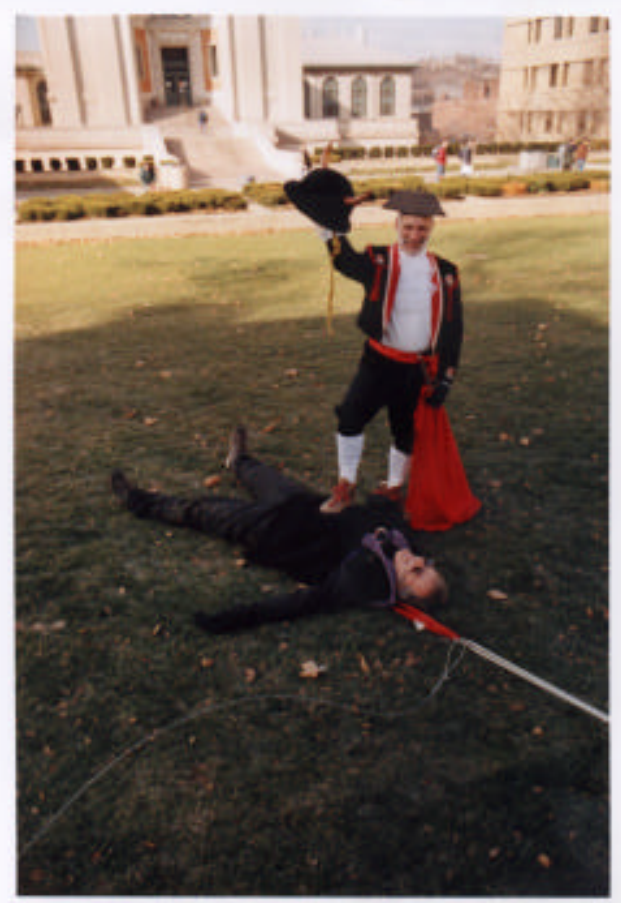

9-“The Bull" is vanquished

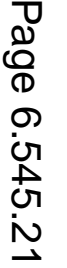


Summary

The five previous examples shared many of the same characteristics. The problems were delivered in very creative manners. The problems were humorous and offbeat, sometimes using unusual materials. The examples were of floating trebuchets, collapsible bridges, ice bridges, cofferdams and towers. All were difficult design problems, especially given the project duration was only 4 weeks. The four-week project length forced the students to be creative in a hurry. Their preliminary design had to be completed within one and a half weeks. The next two weeks were dedicated to preliminary design, detailed design, and construction and testing. The final half-week was used to produce the final project report. The instructors used their judgment to assure that each project was doable in this compressed time frame. Knowledge of many Civil Engineering core courses was prerequisite to solving the problems. (See Table 1) Each project used an instructor as the test object. Each project covered the three levels of design. Tee shirts for each project were distributed (most were highly coveted). Humor was permitted in the final reports (some of it side-splitting).

\begin{tabular}{|l|c|c|c|c|c|}
\hline $\begin{array}{c}\text { PROJECT / } \\
\text { COURSE }\end{array}$ & $\begin{array}{c}\text { MOBILE } \\
\text { COW } \\
\text { TOSSING }\end{array}$ & $\begin{array}{c}\text { MISSION: } \\
\text { PREPOSTEROUS }\end{array}$ & $\begin{array}{c}\text { RUBE } \\
\text { ICEBERG } \\
\text { P.D.S. }\end{array}$ & $\begin{array}{c}\text { JUST } \\
\text { DAM } \\
\text { IT! }\end{array}$ & $\begin{array}{c}\text { WOOLLY } \\
\text { BULLY }\end{array}$ \\
\hline Statics & $\mathbf{X}$ & $\mathbf{X}$ & $\mathbf{X}$ & $\mathbf{X}$ & $\mathbf{X}$ \\
\hline Dynamics & $\mathbf{X}$ & & & & $\mathbf{X}$ \\
\hline Solid Mechanics & $\mathbf{X}$ & $\mathbf{X}$ & $\mathbf{X}$ & $\mathbf{X}$ & $\mathbf{X}$ \\
\hline Structural Analysis & $\mathbf{X}$ & $\mathbf{X}$ & $\mathbf{X}$ & $\mathbf{X}$ & $\mathbf{X}$ \\
\hline Structural Design & $\mathbf{X}$ & $\mathbf{X}$ & $\mathbf{X}$ & $\mathbf{X}$ & $\mathbf{X}$ \\
\hline Material Selection & $\mathbf{X}$ & $\mathbf{X}$ & $\mathbf{X}$ & $\mathbf{X}$ & $\mathbf{X}$ \\
\hline Fluid Mechanics & $\mathbf{X}$ & & $\mathbf{X}$ & $\mathbf{X}$ & \\
\hline Soil Mechanics & & & & $\mathbf{X}$ & \\
\hline
\end{tabular}

Table 1. Required background courses per project

\section{Lessons Learned}

Having taught the course for many years, the instructors have noted many outcomes from these projects. Students develop an esprit de corps and fortify self-confidence. They draw on their background courses to solve real problems. They learn to work effectively in teams. They learn that laughter is a good thing. They have a lasting memory of the institution and a good feeling towards their discipline. 


\section{Acknowledgements}

Larry Cartwright appreciates the help from his colleagues, C.I. Davidson, S.J. Fenves, F.C. McMichael, I.J. Oppenheim, and D. Rehak, who shared teaching responsibilities with him for the senior design course.

\section{LARRY CARTWRIGHT}

Larry Cartwright is a Principal Lecturer at Carnegie Mellon University in Pittsburgh, PA. He received his B.S. and M.S. in Civil Engineering from Carnegie Mellon. He is also the Director of the Civil and Environmental Engineering Laboratories. 